\title{
Measuring the impact of multiple discrimination on depression in Europe
}

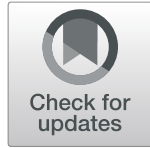

Javier Alvarez-Galvez ${ }^{1 *}$ and Antonio Rojas-Garcia²

\begin{abstract}
Background: The study of the health effects of perceived discrimination based on ethnic and social traits has a long-standing and widespread tradition in epidemiological research, but less attention has been paid to the study of multiple discrimination, particularly its effects on mental health. The present work aims to analyse the association between multiple discrimination and depressive symptoms in Europe, and the impact of contextual socioeconomic circumstances on this relationship.

Methods: In this study, data from the 7th Round of the European Social Survey was used. Given that the outcome variable, CES-D8, is a depression scale from 0 to 24 possible values and the hierarchical organisation of individuals (level-1 units) clustered within countries (level-2 units), a linear multilevel model was carried out.

Results: Our findings suggest that multiple discrimination increases our risk of suffering depressive disorder, but in addition this work provides an important step forward to explain and understand how the relationship between multiple discrimination and depression might vary depending the socioeconomic context. In particular, we can observe that differences in the prevalence of depressive symptoms along multiple discrimination levels decrease as GDP per capita increases among European countries.

Conclusion: This study is relevant since provides new evidence on how the association between multiple discrimination and depression operates at the micro and macro-level context, which is fundamental to understand how macro-economic fluctuations of countries may determine depressive disorders through the effect of single and combined forms of discrimination.
\end{abstract}

Keywords: Multiple discrimination, Depression, Socioeconomic status, Multilevel analysis, Europe

\section{Background}

Depression is one of the most common mental disorders and has been identified as a leading cause of disability $[1,2]$. A recently published report from the World Health Organisation (WHO) in 2017 [3] informs that the global population suffering depression in 2015 is estimated to be $4.4 \%$. Similarly, it has been estimated that the prevalence of depressive disorders in Europe range from 4 to $6 \%$ [3]. However, epidemiological studies have found several sociodemographic factors associated with depression, such as gender, age, marital and socioeconomic status that make certain populations more vulnerable to depressive disorders $[4,5]$.

\footnotetext{
* Correspondence: javier.alvarezgalvez@uca.es

${ }^{1}$ Department of Biomedicine, Biotechnology and Public Health, University of Cadiz, Avda. Ana de Viya, 52, 11009 Cádiz, Spain

Full list of author information is available at the end of the article
}

Social circumstances define the context where individuals live, and thus their health and quality of life [6]. Among other social determinants such as social class, educational attainment, income distribution or material circumstances [7], studies show that discrimination has important consequences on health [8-18]. Literature shows that individuals who perceive themselves to be subjects of discrimination have a higher predisposition to suffer health problems, particularly those related to mental illness such as stress, anxiety, phobias, depression, and even high-risk health behaviours (i.e. smoking tobacco, drinking alcohol, eating disorders, suicide, etc.) that are associated to poor health outcomes [18, 19]. Perceived discrimination has also been found to be connected to specific physical health problems including hypertension, obesity, breast cancer, and other potentially risky behaviour such as substance abuse [17].

(c) The Author(s). 2019 Open Access This article is distributed under the terms of the Creative Commons Attribution 4.0 International License (http://creativecommons.org/licenses/by/4.0/), which permits unrestricted use, distribution, and 
Previous research on the effects of discrimination on health have highlighted the influence of ethnic and racial discrimination on mental and physical health outcomes [19-23]. Studies has demonstrated that discriminated ethnic minorities, including those with Black, Latin, and Asian origin, are associated with larger socioeconomic inequalities and poor health outcomes [12, 24]. However, perceived discrimination based on gender, sexual orientation, language, religion, nationality, social class or disabilities can also lead to poor health outcomes [9, 25-29].

The study of the effects on health of perceived discrimination based on ethnic and social traits has a long-standing and widespread tradition in epidemiological research, but less attention has been paid to the study of multiple discrimination [30]. The concept 'multiple discrimination' describes the specific situation when an individual belongs to more than one disadvantaged group and therefore experiences forms of discrimination of a more complex and severe nature than those subject to discrimination on a single ground [31]. Although literature has broadly assessed the effect of single causes of discrimination, few studies have described whether multiple discrimination increases risk for poor health outcomes. A recent study using survey data from a sample of adults living in Miami (Florida), has revealed that those reporting multiple reasons for discrimination are at increased risk for major depression and subsequent depressive symptoms [32].

Two studies investigating depression across more than 20 European countries, showed that the prevalence of depressive disorders among immigrant and ethnic minorities groups was higher than among natives, which it seemed to be associated with perceived discrimination due to socio-economic conditions and ethnic and racial factors [33, 34]. These findings align with the formation of negative attitudes towards discriminated groups (e.g. immigrants), which has been found related to socioeconomic problems within countries [35]. GDP per capita, inequality, and unemployment are described in literature as contextual determinants that partially explain the variations in diverse types of social rejection. According to this perspective, discrimination might be considered as the product of competition for scarce socio-economic resources (e.g. jobs, income inequality, and social benefits). Therefore, it is essential to analyse how the association between multiple discrimination and mental health might change depending on these contextual variations.

In order to address this gap in the literature, this study aims to investigate the association between multiple discrimination and depression in Europe. Specifically, the effect of countries' socioeconomic circumstances over the relationship between multiple discrimination and depression will be analysed. The objectives of this study are based on the following hypotheses:
- H1: The effect of multiple discrimination on depression is higher than the effect of single causes of discrimination.

- H2: The association between multiple discrimination and depression varies among European countries.

- H3. The effect of multiple discrimination on depression is lower in economically prosperous countries (i.e. those characterised by high GPD, low risk of poverty, and/or low unemployment).

\section{Methods}

\section{Data and variables}

With the aim of studying the association between multiple discrimination and depression in Europe, and the impact of socioeconomic context on this relationship, data from the 7th Round of the European Social Survey [36] were used. The ESS7 dataset is composed by a sample of 40,185 individuals, which are aggregated around a total of 21 countries. These countries are the following: Austria (AU), Belgium (BE), the Czech Republic (CZ), Denmark (DK), Estonia (EE), Finland (FI), France (FR), Germany (DE), Hungary (HU), Ireland (IE), Israel (IL), Lithuania (LT), the Netherlands (NL), Norway (NO), Poland (PL), Portugal (PT), Slovenia (SI), Spain (ES), Sweden (SE), Switzerland $(\mathrm{CH})$, and the United Kingdom (UK). The target population of ESS7 included individuals over 15 years of age who are residents in Europe within private households, regardless of nationality, citizenship, language or legal status. For additional information, a complete description of the survey specifications can be found in the ESS7 Documentation Report [37]. In this study focused in European countries, Israel was excluded from the final sample due to comparative purposes, since we considered that socio-cultural differences might affect to the interpretation of results.

The dependent variable to be explained in this study is depression. This outcome variable has been developed through the eight-item short version of the Center for Epidemiologic Studies Depression Scale (CES-D8) [38]. The resulting indicator measures depressive symptoms defined by the American Psychiatric Association's Diagnostic and Statistical Manual (DSM-5) for a major depressive episode in a scale whose scores range from 0 to 24 , with higher values indicating a greater number of depressive symptoms [30, 31]. The item responses were assessed on a 4-point scale where 0 represents the category "rarely or none of the time", 1 "some of the time", 2 "most of the time", and finally 3 "most or all of the time". In the ESS7 questionnaire, the items who composed the scale were the following: "Using this card, please tell me how much of the time during the past week...", (E20) “...you felt depressed?”, (E21) “...you felt that everything you did was an effort?", (E22) “...your sleep was restless?”, (E23) “...you were happy?”, (E24) 
“...you felt lonely?”, (E25) “...you enjoyed life?”, (E26) “...you felt sad?", and (E27) "...you could not get going?". Therefore, the depression variable (CES-D8) was used as a continuous scale in which higher scores depicted a greater level or intensity of depressive symptoms [39]. The internal consistency reliability coefficients of the 8 -item scale were satisfactory (Cronbach $\alpha=0.79$ ).

In the multilevel model, two types of explanatory variables were included in the analysis to adjust the relationship between multiple discrimination and depression: individual attributes and aggregate variables. At the individual level, multiple discrimination was the main predictor to be assessed, where 0 'No discrimination', 1 'One reason for discrimination', 2 'two or more reason for discrimination'. This variable was developed using the question of the ESS7 questionnaire 'On what grounds is your group discriminated against?' with the following categories of perceived discrimination based on: colour or race, nationality, religion, language, ethnic group, age, gender, sexuality, disability, or other. Following the criteria of Gayman and Barragan [32], the aggregation in three categories (i.e. no discrimination, one reason for discrimination, and two or more reasons) was aimed to increase the statistical power in the sample of people reporting discrimination.

The relationship between the depression score and multiple discrimination was adjusted by: gender where 0 'male', 1 'female'; age group (1 '18-29', 2 '30-39', 3 '4049', 4 ' ‘50-59', 5 '60-69', 6 '> 70'); education measured by the International Standard Classification of Education (ISCED) levels: primary education or less (1 'ISCED 01 '), lower secondary (2 'ISCED 2'), upper secondary (3 'ISCED 3'), post-secondary (4 'ISCED 4'), and tertiary education (5 'ISCED 5-6'); and household total net income in euros per month (measured in quartiles). The sample characteristics for the variables in the model are described in Table 1.

At the country level, the effect of three predictors were assessed in the multilevel models: (1) risk of poverty rate, this variable describes the share of people below $60 \%$ of the median equivalized disposable income in the country after social transfers; (2) unemployment rate, which represents the number of people unemployed as a percentage of the active population (excluding economically inactive individuals such as preschool and school children, students and pensioners); and (3) gross domestic product (GDP) per capita, as a measure of the overall size of economy for every country. These country-level data were extracted from Eurostat, the statistical office of the European Union (more information on the Eurostat database: https://ec.europa.eu/eurostat).

\section{Statistical analysis}

Given that the dependent variable, CES-D8, is a scale from 0 to 24 possible values and the hierarchical
Table 1 Sample characteristics $(n=40,185)$

\begin{tabular}{lll}
\hline CES-D8 & Depressive symptoms & $14.8 \%(5785)$ \\
Multiple discrimination & No discrimination & $92.0 \%(36,961)$ \\
& One reason & $5.6 \%(2236)$ \\
& Two or more reasons & $2.5 \%(987)$ \\
Gender & Male & $47.0 \%(18,870)$ \\
Age group & Female & $53.0 \%(21,292)$ \\
& $18-29$ years & $18.3 \%(7334)$ \\
& $30-39$ years & $15.4 \%(6158)$ \\
& $40-49$ years & $16.4 \%(6554)$ \\
& $50-59$ years & $17.2 \%(6894)$ \\
& $60-69$ years & $16.7 \%(6690)$ \\
& $>70$ years & $16.1 \%(6454)$ \\
Education (ISCED) & Primary education or less & $10.2 \%(4085)$ \\
& Lower secondary & $16.9 \%(6759)$ \\
& Upper secondary & $35.8 \%(14,307)$ \\
& Post-secondary & $14.2 \%(5671)$ \\
& Tertiary education & $22.8 \%(9096)$ \\
Household income & Quartile 1 & $31.0 \%(9894)$ \\
& Quartile 2 & $21.9 \%(6983)$ \\
& Quartile 3 & $30.6 \%(9749)$ \\
& Quartile 4 & $16.5 \%(5262)$ \\
\hline
\end{tabular}

structure of individuals (level-1 units) clustered within countries (level-2 units), a multilevel model was carried out to work with this nested structure $(\mathrm{ICC}=0.05)$. Considering that we have a clustered-data structure of individuals within countries, it is statistically necessary to organize all individual units in a multilevel model of independent clusters or groups of observations [40]. This analytical solution enables the simultaneous study of variations in depression levels (CES-D8) related to individuals within their particular countries. The multilevel model can be described as follows:

$$
Y_{i j}=\gamma_{00}+\gamma_{10} X_{i j}+\gamma_{01} Z_{j}+\gamma_{11} Z_{j} X_{i j}+u_{0 j}+e_{i j}
$$

Where the u-term $u_{0 j}$ in Eq. 1 is (random) residual error at the country level, and the e-term $e_{i j}$ at the individual level. These errors are assumed to have mean of zero, and to be independent from the residual error. While the predictors $X_{i}$ and $Z_{j}$ correspond to the level 1 and level 2 respectively. In order to understand the aggregated effect of clustered-data, different models are performed. Initially, the effect of multiple discrimination is assumed to be fixed across country units, but there having a random intercept that considers the variations in responses between the countries under analysis. In a second step, the effect of multiple discrimination is assumed to vary between countries so that we can observe 
possible variations in the relationship between multiple discrimination and the depression score among country level units. Random intercept and random slopes model are tested in separated models to study this association. Errors are considered to be constant and are not correlated between level 2 units. Model are estimated using Restricted Maximum Likelihood.

Stata $^{\circ} 14.0$ was used to perform data analysis, including descriptive and inferential statistics.

\section{Results}

In order to gain a better understanding of the relationships to be modelled, Table 2 describes the mean of the depressive symptoms by countries for the five individual-level predictors. To facilitate the interpretation of this scale, the table uses a colour coding based on the highest, median, and lowest value of the distribution of each predictor across the European countries in the sample.
On average, Northern European countries such as Denmark, Finland, Norway and Sweden present lower depressive symptoms, while Southern and Eastern countries present higher scores. In particular, Portugal, Lithuania, and Hungary are the countries that show poorer results in the depression scale. With the exception of Denmark, Switzerland, and Norway, depressive symptoms seem to be more prevalent among females, older adults (in particular older groups over 70 years old), and people with low socioeconomic status (i.e. low educational attainment and low-income groups). Finally, in the last column of the table, we can observe that those who feel themselves as being discriminated by more than two grounds (i.e. people suffering multiple discrimination) present a higher mean score in the CES-D8 scale. On average, multiple discrimination increases mean depressive symptoms in a $28 \%$ among European countries, but this percentage can be even doubled depending on the country (e.g. in Hungary, the mean score of depressive symptoms is 6.995 , but this

Table 2 Mean depressive symptoms by countries, socio-demographic characteristics and multiple discrimination $(n=40,185)$

\begin{tabular}{|c|c|c|c|c|c|c|c|c|c|c|c|c|c|c|c|c|c|c|c|}
\hline & $\stackrel{\frac{\pi}{0}}{\circ}$ & $\sum_{\Sigma}^{\frac{\pi}{\pi}}$ & 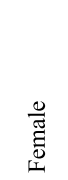 & $\begin{array}{c}\text { సે } \\
\infty\end{array}$ & 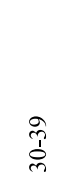 & $\begin{array}{l}\stackrel{q}{q} \\
\text { ơ }\end{array}$ & $\begin{array}{l}\hat{n} \\
\text { in } \\
\text { हn }\end{array}$ & 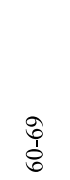 & $\stackrel{R}{\wedge}$ & 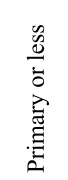 & 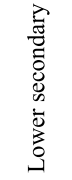 & 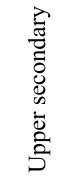 & 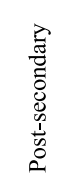 & 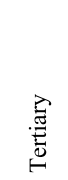 & 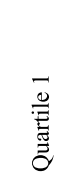 & 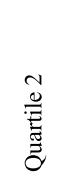 & 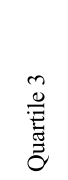 & 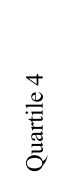 & 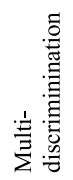 \\
\hline Austria & 4.907 & 4.622 & 5.165 & 3.956 & 4.567 & 4.813 & 5.049 & 4.934 & 6.168 & 6.779 & 5.677 & 4.749 & 4.135 & 4.463 & 5.742 & 4.981 & 4.232 & 3.957 & 6.178 \\
\hline Belgium & 4.964 & 4.374 & 5.569 & 5.155 & 4.743 & 5.047 & 4.950 & 4.471 & 5.388 & 5.773 & 5.455 & 4.797 & 5.066 & 4.348 & 6.106 & 5.238 & 4.487 & 4.198 & 5.591 \\
\hline Switzerland & 4.197 & 3.929 & 4.464 & 4.411 & 4.049 & 4.320 & 4.428 & 3.861 & 3.949 & 5.578 & 4.838 & 4.130 & 3.727 & 3.798 & 4.972 & 4.057 & 3.864 & 3.451 & 6.852 \\
\hline $\begin{array}{r}\text { Czech } \\
\text { Republic }\end{array}$ & 6.410 & 5.986 & 6.718 & 4.559 & 5.387 & 6.358 & 7.398 & 7.173 & 8.698 & 4.833 & 6.696 & 6.439 & 6.661 & 5.857 & 7.841 & 6.366 & 5.674 & 5.677 & 8.549 \\
\hline Germany & 5.440 & 4.885 & 6.009 & 5.501 & 5.026 & 5.429 & 5.726 & 5.103 & 5.712 & 5.768 & 6.851 & 5.693 & 5.101 & 4.667 & 6.871 & 5.486 & 5.058 & 4.489 & 6.955 \\
\hline Denmark & 4.504 & 4.145 & 4.888 & 5.108 & 4.737 & 4.772 & 4.414 & 3.948 & 3.751 & 5.000 & 5.322 & 4.443 & 3.699 & 4.279 & 5.503 & 4.753 & 4.160 & 3.856 & 7.216 \\
\hline Estonia & 6.276 & 5.819 & 6.593 & 5.523 & 5.396 & 5.976 & 6.390 & 6.882 & 7.408 & 9.783 & 7.112 & 6.397 & 6.223 & 5.507 & 7.115 & 5.875 & 5.234 & 3.899 & 7.222 \\
\hline Spain & 5.915 & 5.100 & 6.771 & 5.089 & 5.765 & 5.487 & 6.290 & 5.669 & 7.339 & 7.145 & 5.925 & 5.357 & 5.207 & 5.035 & 7.429 & 6.188 & 4.738 & 4.580 & 6.984 \\
\hline Finland & 4.383 & 4.189 & 4.572 & 4.549 & 4.119 & 4.314 & 4.446 & 4.091 & 4.793 & 4.896 & 4.555 & 4.323 & 4.256 & 4.223 & 5.389 & 4.346 & 3.955 & 3.607 & 6.388 \\
\hline France & 5.295 & 4.528 & 5.995 & 4.899 & 5.316 & 5.134 & 5.379 & 5.182 & 5.914 & 6.304 & 5.537 & 5.337 & 4.977 & 4.570 & 6.684 & 5.245 & 4.610 & 3.940 & 7.024 \\
\hline $\begin{array}{l}\text { United } \\
\text { Kingdom }\end{array}$ & 5.376 & 5.028 & 5.664 & 5.176 & 5.488 & 5.466 & 5.811 & 5.186 & 5.077 & 6.262 & 5.547 & 5.205 & 5.480 & 4.543 & 6.571 & 5.027 & 4.653 & 4.021 & 6.503 \\
\hline Hungary & 6.995 & 6.491 & 7.368 & 5.051 & 5.391 & 6.519 & 7.123 & 7.789 & 9.895 & 1.167 & 8.667 & 6.715 & 6.202 & 5.407 & 10.684 & 7.899 & 6.623 & 4.824 & 10.043 \\
\hline Ireland & 4.577 & 4.257 & 4.849 & 4.237 & 4.148 & 4.452 & 4.664 & 4.663 & 5.363 & 6.122 & 5.193 & 3.895 & 4.074 & 3.858 & 5.672 & 3.691 & 3.347 & 3.319 & 5.748 \\
\hline Lithuania & 7.089 & 6.492 & 7.460 & 4.916 & 6.117 & 6.562 & 7.496 & 8.302 & 9.257 & 8.209 & 7.649 & 7.331 & 7.316 & 5.859 & 9.026 & 7.316 & 6.419 & 5.127 & 9.305 \\
\hline Netherlands & 4.679 & 4.234 & 5.040 & 4.625 & 4.434 & 4.698 & 4.642 & 4.406 & 5.278 & 6.007 & 5.179 & 4.626 & 4.057 & 3.965 & 6.439 & 4.821 & 3.874 & 3.480 & 6.936 \\
\hline Norway & 4.031 & 3.751 & 4.348 & 5.025 & 4.201 & 3.833 & 3.622 & 3.400 & 3.673 & 5.250 & 4.612 & 4.229 & 3.528 & 3.683 & 4.808 & 3.810 & 3.724 & 3.266 & 5.373 \\
\hline Poland & 5.322 & 4.601 & 5.927 & 4.244 & 3.890 & 4.432 & 6.041 & 6.440 & 7.947 & 8.963 & 6.019 & 4.649 & 6.109 & 3.979 & 7.075 & 5.342 & 4.603 & 3.967 & 7.246 \\
\hline Portugal & 7.135 & 5.940 & 8.127 & 6.086 & 5.813 & 6.917 & 7.179 & 7.577 & 8.366 & 8.464 & 6.122 & 6.346 & 5.745 & 5.534 & 8.436 & 6.794 & 6.095 & 5.226 & 9.761 \\
\hline Sweden & 4.727 & 4.212 & 5.237 & 5.119 & 4.984 & 4.527 & 4.463 & 4.226 & 4.919 & 5.223 & 4.455 & 4.880 & 4.406 & 4.715 & 5.918 & 4.911 & 4.718 & 3.925 & 6.648 \\
\hline Slovenia & 5.060 & 4.412 & 5.603 & 4.517 & 4.317 & 4.212 & 4.905 & 5.306 & 7.092 & 7.176 & 6.097 & 4.929 & 4.671 & 4.189 & 6.405 & 5.059 & 4.181 & 3.735 & 5.594 \\
\hline Total & 5.393 & 4.847 & 5.873 & 4.856 & 4.949 & 5.233 & 5.581 & 5.438 & 6.360 & 6.830 & 5.911 & 5.352 & 5.081 & 4.632 & 6.634 & 5.316 & 4.671 & 4.163 & 6.895 \\
\hline
\end{tabular}

Note: Green colour indicates a lower mean of depressive symptoms and red colour a higher mean of depressive symptoms 
score increases to 10.043 for those with multiple discrimination).

To answer our initial research hypothesis, Table 3 presents the results of six random intercept multilevel models with main effects and cross-level interactions between level-1 and level-2 predictors. Models 1 to 3 includes the individual-level predictors (i.e. multiple discrimination, gender, age, education, and income), and step by step the effect of separated level 2 predictors on the depression score are added. Cross-level interactions are included in models 4 to 6 . At the individual level, multiple discrimination (i.e. being discriminated for two or more reasons) shows a positive correlation with the depression scale (CES-D8), which means that combined types of discrimination may determine higher levels of depressive symptoms. The association between multiple discrimination and the depression score is statistically significant across all the models (with coefficients

Table 3 Results for random intercept multilevel models

\begin{tabular}{|c|c|c|c|c|c|c|}
\hline Variable & Model 1 & Model 2 & Model 3 & Model 4 & Model 5 & Model 6 \\
\hline One reason discrimination & $1.629^{* * *}(0.099)$ & $1.629^{* * *}(0.099)$ & $1.629^{* * *}(0.099)$ & $1.166^{* * *}(0.350)$ & $1.497^{* * *}(0.222)$ & $1.994^{* * *}(0.425)$ \\
\hline Two or more reasons & $2.055^{* * *}(0.166)$ & $2.056^{* * *}(0.166)$ & $2.057^{* * *}(0.166)$ & $2.547^{* * *}(0.579)$ & $2.504^{* * *}(0.399)$ & $3.392^{* * *}(0.702)$ \\
\hline Female & $0.807^{* * *}(0.044)$ & $0.807^{* * *}(0.044)$ & $0.806^{* * *}(0.044)$ & $0.807^{* * *}(0.044)$ & $0.807^{* * *}(0.044)$ & $0.808(0.044)$ \\
\hline $30-39$ & $0.192^{* * * *}(0.079)$ & $0.193^{* * *}(0.079)$ & $0.192^{* * *}(0.079)$ & $0.192^{* * *}(0.079)$ & $0.193^{* * *}(0.079)$ & $0.191^{* * *}(0.079)$ \\
\hline $40-49$ & $0.463^{* * *}(0.077)$ & $0.463^{* * *}(0.077)$ & $0.463^{* * *}(0.077)$ & $0.4634^{* * * *}(0.077)$ & $0.464^{* * *}(0.077)$ & $0.461^{* * * *}(0.077)$ \\
\hline $50-59$ & $0.620^{* * *}(0.075)$ & $0.620^{* * *}(0.075)$ & $0.620^{* * *}(0.075)$ & $0.620^{* * *}(0.075)$ & $0.621^{* * *}(0.075)$ & $0.617^{* * *}(0.075)$ \\
\hline $60-69$ & $0.210^{* * *}(0.076)$ & $0.211^{* * *}(0.076)$ & $0.210^{* * *}(0.076)$ & $0.209^{* * *}(0.076)$ & $0.212^{* * *}(0.076)$ & $0.205^{* * * *}(0.076)$ \\
\hline$>70$ & $0.546^{* * *}(0.081)$ & $0.547^{* * *}(0.081)$ & $0.547^{* * *}(0.081)$ & $0.544^{* * *}(0.081)$ & $0.547^{* * *}(0.081)$ & $0.542^{* * * *}(0.081)$ \\
\hline Lower secondary & $-0.336^{* * *}(0.093)$ & $-0.335^{* * *}(0.093)$ & $-0.336^{* * *}(0.092)$ & $-0.338^{* * *}(0.092)$ & $-0.335^{* * *}(0.092)$ & $-0.339^{* * *}(0.092)$ \\
\hline Upper secondary & $-0.926^{* * *}(0.088)$ & $-0.925^{* * *}(0.088)$ & $-0.926^{* * *}(0.088)$ & $-0.927^{* * *}(0.088)$ & $-0.925^{* * *}(0.088)$ & $-0.927^{* * *}(0.088)$ \\
\hline Post-secondary & $-0.981^{* * *}(0.098)$ & $-0.980^{* * *}(0.098)$ & $-0.979^{* * *}(0.098)$ & $-0.983^{* * * *}(0.098)$ & $-0.979^{* * *}(0.098)$ & $-0.982^{* * *}(0.098)$ \\
\hline Tertiary & $-1.114^{* * *}(0.094)$ & $-1.113^{* * *}(0.094)$ & $-1.113^{* * *}(0.094)$ & $-1.116^{* * *}(0.094)$ & $-1.113^{* * *}(0.094)$ & $-1.114^{* * *}(0.094)$ \\
\hline Quartile 2 & $-1.149^{* * *}(0.062)$ & $-1.150^{* * *}(0.062)$ & $-1.150^{* * *}(0.062)$ & $-1.150^{* * *}(0.062)$ & $-1.150^{* * *}(0.062)$ & $-1.151^{* * *}(0.062)$ \\
\hline Quartile 3 & $-1.620^{* * *}(0.059)$ & $-1.621^{* * *}(0.059)$ & $-1.621^{* * *}(0.059)$ & $-1.621^{* * *}(0.059)$ & $-1.621^{* * *}(0.059)$ & $-1.623^{* * *}(0.059)$ \\
\hline Quartile 4 & $-2.102^{* * *}(0.073)$ & $-2.102^{* * *}(0.073)$ & $-2.102^{* * * *}(0.073)$ & $-2.103^{* * *}(0.073)$ & $-2.102^{* * * *}(0.073)$ & $-2.103^{* * *}(0.073)$ \\
\hline Risk of poverty & $0.088^{* * * *}(0.026)$ & & & $0.088^{* * *}(0.027)$ & & \\
\hline One reason * Risk Pov. & & & & $0.021(0.015)$ & & \\
\hline Two or more * Risk Pov. & & & & $-0.022(0.025)$ & & \\
\hline Unemploy. & & $0.066(0.039)$ & & & $0.066(0.039)$ & \\
\hline One reason * Unemploy. & & & & & $0.014(0.021)$ & \\
\hline Two or more * Unemploy. & & & & & $-0.050(0.040)$ & \\
\hline GDP per capita & & & $-0.023^{* * * *}(0.004)$ & & & $-0.023^{* * *}(0.004)$ \\
\hline One reason * GDP & & & & & & $-0.003(0.004)$ \\
\hline Two or more reasons * GDP & & & & & & $-0.012^{* *}(0.006)$ \\
\hline Constant & $4.412^{* * *}(0.610)$ & $5.722^{* * *}(0.434)$ & $8.890^{* * *}(0.493)$ & $4.429^{* * *}(0.612)$ & $5.721^{* * *}(0.434)$ & $8.890^{* * * *}(0.492)$ \\
\hline Level 2 (sig_u) & $-0.317^{* *}(0.165)$ & $-0.152(0.164)$ & $-0.565^{* * *}(0.167)$ & $-0.316^{*}(0.165)$ & $-0.152(0.164)$ & $-0.565^{* * *}(0.167)$ \\
\hline Level 1 (sig_e) & $1.315^{* * *}(0.004)$ & $1.315^{* * *}(0.004)$ & $1.315^{* * *}(0.004)$ & $1.315^{* * *}(0.004)$ & $1.315^{* * *}(0.004)$ & $1.315^{* * * *}(0.004)$ \\
\hline Log likelihood & $-8.0 e+04$ & $-8.0 e+04$ & $-8.0 e+04$ & $-8.0 e+04$ & $-8.0 e+04$ & $-8.0 e+04$ \\
\hline Wald Chi Square & 2985.123 & 2975.934 & 3005.669 & 2988.161 & 2978.154 & 3010.905 \\
\hline $\mathrm{AIC}$ & $1.6 e+05$ & $1.6 e+05$ & $1.6 e+05$ & $1.6 e+05$ & $1.6 e+05$ & $1.6 e+05$ \\
\hline $\mathrm{BIC}$ & $1.6 e+05$ & $1.6 e+05$ & $1.6 e+05$ & $1.6 e+05$ & $1.6 e+05$ & $1.6 e+05$ \\
\hline Countries & 20 & 20 & 20 & 20 & 20 & 20 \\
\hline
\end{tabular}


between 2.055 and 3.392), even when controlling by socio-demographics and socioeconomic predictors. As previously observed, depressive symptoms increase among females (0.807-0.808), when respondents age increases (in particular in the 50-59 age group, 0.622), and for those with lower socioeconomic status, i.e. in low education level $(-0.340)$ and low-income groups $(-1.147)$.

In order to study if the association of multiple discrimination and the prevalence of depressive symptoms is weaker in economically prosperous countries (H3), three level 2 predictors were included at the aggregated level: risk of poverty (model 1), unemployment (model 2), and GDP per capita (model 3) over individual-level depressive symptoms. As we can observe, risk of poverty at the macro-level is positively associated $(0.088)$ to the prevalence of depressive symptoms (model 1), and, on the contrary, aggregated GDP per capita is negatively related $(-0.023)$ to depressive symptoms (model 3). Macro-level unemployment was not found associated to depressive symptoms in model $2(0.066)$. These results indicate that economic prosperity -defined by either a low risk of poverty or higher GDP per capita - is positive for mental health but contextual unemployment is rather neutral. Therefore, favourable socioeconomic circumstances at the country-level might decrease the rate of depressive symptoms among European population.

With the aim to find out whether the relationship of multiple discrimination on depressive symptoms varies along contextual socioeconomic conditions, models 4-6 include the interaction terms between the level 2 predictors and multiple discrimination at the individual-level. Cross-level interactions were only statistically significant in model 6 where the effect of multiple discrimination and GDP per capita were combined $(-0.012 ; p<.05)$, but interactions in models $4-5$ were not. Consistent with hypotheses $\mathrm{H} 2$ and H3, GDP moderates the effect of multiple discrimination on the prevalence of depressive symptoms, which means that mental inequalities based related to multiple discrimination will be lower in wealthier countries.

Table 4 shows similar results for random slope coefficient models, although a higher variability in the model decrease the level of significance in some models (e.g. model 4 and 5). However, in model 6 we can observe the same pattern to that found in Table 3, i.e. the differences in CES-D8 scale between multiple discrimination levels decrease as GDP per capita increases.

To have a better understanding of the moderation effect of GDP per capita on the association of multiple discrimination on depressive symptoms, this relationship has been described in Fig. 1. Random intercepts models for single and interaction effects are depicted above, and random slope models are described below. These graphs confirm that the effect of multiple discrimination on depressive symptoms is higher than the effect of single causes of discrimination ( $\mathrm{H} 1)$, the association between multiple discrimination and the depression scale significantly differs among European countries (H2), and the impact of multiple discrimination on depressive symptoms is lower in countries having favourable socioeconomic circumstances, in particular GPD per capita (H3).

Finally, for a better identification of the relationship between multiple discrimination and the prevalence of depressive symptoms among European countries, the main effect has been plotted in Fig. 2. According to the initial descriptive results in Table 2, the stronger effect of multiple discrimination on the depression scale has been found in the East and South European countries, and this relationship is particularly strong in countries such as Hungary, Czech Republic, Lithuania and Portugal.

\section{Discussion}

Although there is a vast amount of literature on discrimination and mental health, some of the main issues on this topic remain unclear. This study aimed to investigate three questions around the relationship between multiple discrimination and depression: i) how is multiple discrimination associated with depression in Europe, using a continuous measure of depressive symptoms (CES-D8); ii) how this relationship varies among European countries; and specifically, iii) how the moderation effect of countries' socioeconomic circumstances influence the relationship between multiple discrimination and depressive symptoms. To answer these research questions a multilevel strategy has been implemented to explain and understand the negative relationship of multiple discrimination on depression in Europe according contextual socioeconomic differences. Overall, findings show that countries from Northern Europe present lower rates of depressive symptoms; multiple discrimination is positively associated to depressive symptoms, and macro-level variables such as GDP, risk of poverty and unemployment have correlated with depression scores in different ways.

As hypothesised, our findings suggest that multiple discrimination may increase the risk of suffering depressive disorder, these results support what has been found in previous research [41, 42]. In addition, this study show that the relationship between multiple discrimination and depression may be context-dependent. In this regard, the association may vary depending on the socioeconomic context. In particular, differences in the prevalence of depressive symptoms across multiple discrimination levels decrease as GDP per capita increases. However macrolevel unemployment was not statistically significant in any cross-level interaction between multiple discrimination 
Table 4 Results for the random slope coefficient models

\begin{tabular}{|c|c|c|c|c|c|c|}
\hline Variable & Model 1 & Model 2 & Model 3 & Model 4 & Model 5 & Model 6 \\
\hline One reason disc. & $1.606^{* * *}(0.383)$ & $1.603^{* * *}(0.430)$ & $1.629^{* * *}(0.303)$ & $1.297(1.362)$ & $1.600^{*}(0.905)$ & $1.715^{* *}(1.090)$ \\
\hline Two or more reasons & $2.077^{* * *}(0.414)$ & $2.098^{* * *}(0.458)$ & $2.137^{* * *}(0.339)$ & $2.579^{*}(1.450)$ & $2.451^{* *}(0.970)$ & $4.188^{* * *}(1.257)$ \\
\hline Female & $0.808^{* * *}(0.044)$ & $0.808^{* * *}(0.044)$ & $0.808^{* * *}(0.044)$ & $0.808^{* * *}(0.044)$ & $0.808^{* * *}(0.044)$ & $0.808^{* * *}(0.044)$ \\
\hline $30-39$ & $0.193^{* * *}(0.079)$ & $0.193^{* * *}(0.079)$ & $0.193^{* * *}(0.079)$ & $0.193^{* * *}(0.079)$ & $0.193^{* * *}(0.079)$ & $0.192^{* * *}(0.079)$ \\
\hline $40-49$ & $0.462^{* * *}(0.077)$ & $0.463^{* * *}(0.077)$ & $0.462^{* * *}(0.077)$ & $0.462^{* * *}(0.077)$ & $0.463^{* * *}(0.077)$ & $0.461^{* * *}(0.077)$ \\
\hline $50-59$ & $0.622^{* * *}(0.075)$ & $0.623^{* * *}(0.075)$ & $0.622^{* * *}(0.075)$ & $0.622^{* * *}(0.075)$ & $0.623^{* * *}(0.075)$ & $0.621^{* * *}(0.075)$ \\
\hline $60-69$ & $0.206^{* * *}(0.076)$ & $0.207^{* * *}(0.076)$ & $0.207^{* * *}(0.076)$ & $0.207^{* * *}(0.076)$ & $0.208^{* * *}(0.076)$ & $0.206^{* * *}(0.076)$ \\
\hline$>70$ & $0.545^{* * *}(0.081)$ & $0.546^{* * *}(0.081)$ & $0.545^{* * *}(0.081)$ & $0.545^{* * *}(0.081)$ & $0.546^{* * *}(0.081)$ & $0.544^{* * *}(0.081)$ \\
\hline Lower secondary & $-0.340^{* * *}(0.093)$ & $-0.340^{* * *}(0.093)$ & $-0.339^{* * *}(0.092)$ & $-0.340^{* * *}(0.093)$ & $-0.340^{* * *}(0.093)$ & $-0.339^{* * *}(0.092)$ \\
\hline Upper secondary & $-0.924^{* * *}(0.088)$ & $-0.925^{* * *}(0.088)$ & $-0.924^{* * *}(0.088)$ & $-0.924^{* * *}(0.088)$ & $-0.924^{* * *}(0.088)$ & $-0.923^{* * *}(0.088)$ \\
\hline Post-secondary & $-0.981^{* * *}(0.098)$ & $-0.980^{* * *}(0.098)$ & $-0.978^{* * *}(0.098)$ & $-0.980^{* * *}(0.098)$ & $-0.979^{* * *}(0.098)$ & $-0.978^{* * *}(0.098)$ \\
\hline Tertiary & $-1.112^{* * *}(0.094)$ & $-1.112^{* * *}(0.094)$ & $-1.110^{* * *}(0.094)$ & $-1.112^{* * *}(0.094)$ & $-1.112^{* * *}(0.094)$ & $-1.110^{* * * *}(0.094)$ \\
\hline Quartile 2 & $-1.147^{* * *}(0.062)$ & $-1.147^{* * *}(0.062)$ & $-1.148^{* * *}(0.062)$ & $-1.147^{* * *}(0.062)$ & $-1.147^{* * *}(0.062)$ & $-1.148^{* * *}(0.062)$ \\
\hline Quartile 3 & $-1.618^{* * *}(0.059)$ & $-1.618^{* * *}(0.059)$ & $-1.619^{* * *}(0.059)$ & $-1.618^{* * *}(0.059)$ & $-1.618^{* * *}(0.059)$ & $-1.620^{* * *}(0.059)$ \\
\hline Quartile 4 & $-2.095^{* * *}(0.073)$ & $-2.095^{* * *}(0.073)$ & $-2.096^{* * *}(0.073)$ & $-2.095^{* * *}(0.073)$ & $-2.094^{* * *}(0.073)$ & $-2.096^{* * *}(0.073)$ \\
\hline Risk of poverty & $0.086^{* * *}(0.026)$ & & & $0.088^{* * *}(0.041)$ & & \\
\hline One reason * Risk Pov. & & & & $0.014(0.060)$ & & \\
\hline Two or more * Risk Pov. & & & & $-0.023(0.063)$ & & \\
\hline Unemploy. & & $0.056(0.037)$ & & & $0.066(0.058)$ & \\
\hline One reason * Unemploy. & & & & & $0.001(0.085)$ & \\
\hline Two or more * Unemploy. & & & & & $-0.38(0.092)$ & \\
\hline GDP per capita & & & $-0.027^{* * *}(0.004)$ & & & $-0.023^{* * *}(0.006)$ \\
\hline One reason * GDP & & & & & & $-0.001(0.009)$ \\
\hline Two or more reasons * GDP & & & & & & $-0.018^{* *}(0.011)$ \\
\hline Constant & $4.457^{* * *}(0.623)$ & $5.809^{* * *}(0.463)$ & $9.323^{* * *}(0.523)$ & $4.424^{* * *}(0.931)$ & $5.716^{* * *}(0.629)$ & $8.855^{* * *}(0.708)$ \\
\hline Level 2 (sig_u) & $0.120^{* *}(0.140)$ & $0.244^{*}(0.128)$ & $-0.143^{* * *}(0.156)$ & $-0.118^{*}(0.139)$ & $-0.240^{*}(0.128)$ & $-0.185^{* * *}(0.157)$ \\
\hline Level 1 (sig_e) & $1.314^{* * *}(0.004)$ & $1.314^{* * *}(0.004)$ & $1.314^{* * *}(0.004)$ & $1.314^{* * *}(0.004)$ & $1.314^{* * * *}(0.004)$ & $1.314^{* * *}(0.004)$ \\
\hline Log likelihood & $-8.0 e+04$ & $-8.0 e+04$ & $-8.0 e+04$ & $-8.0 e+04$ & $-8.0 e+04$ & $-8.0 e+04$ \\
\hline Wald Chi Square & 2520.983 & 2504.387 & 2571.585 & 2521.525 & 2504.820 & 2581.643 \\
\hline AIC & $1.6 e+05$ & $1.6 e+05$ & $1.6 e+05$ & $1.6 e+05$ & $1.6 e+05$ & $1.6 e+05$ \\
\hline $\mathrm{BIC}$ & $1.6 e+05$ & $1.6 e+05$ & $1.6 \mathrm{e}+05$ & $1.6 e+05$ & $1.6 e+05$ & $1.6 e+05$ \\
\hline Countries & 20 & 20 & 20 & 20 & 20 & 20 \\
\hline
\end{tabular}

Note: Significance level ${ }^{* * *} p<0.01,{ }^{* *} p<0.05,{ }^{*} p<0.10$. Standard errors in parenthesis $(n=40,185)$

and risk of poverty, which is possibly due to the lower variability in these macro-indicators that might affect to polarised groups (i.e. basically unemployed and those in risk of poverty). Although further evidence is needed to answer this analytical inconsistency, one possible explanation is that macro-level variations in unemployment and risk of poverty rates do not affect the whole population but, in particular, those groups at the bottom of social hierarchy. In any case, our results would be consistent with what has been investigated in other studies [32, 41-43].

Aligned with previous research, the present study has explored how multiple discrimination may be a risk factor for depression [32], however, it also provides an important step forward to explain and understand how the relationship between multiple discrimination and depressive symptoms might vary in relation to other variables. For instance, the effect of multiple discrimination 

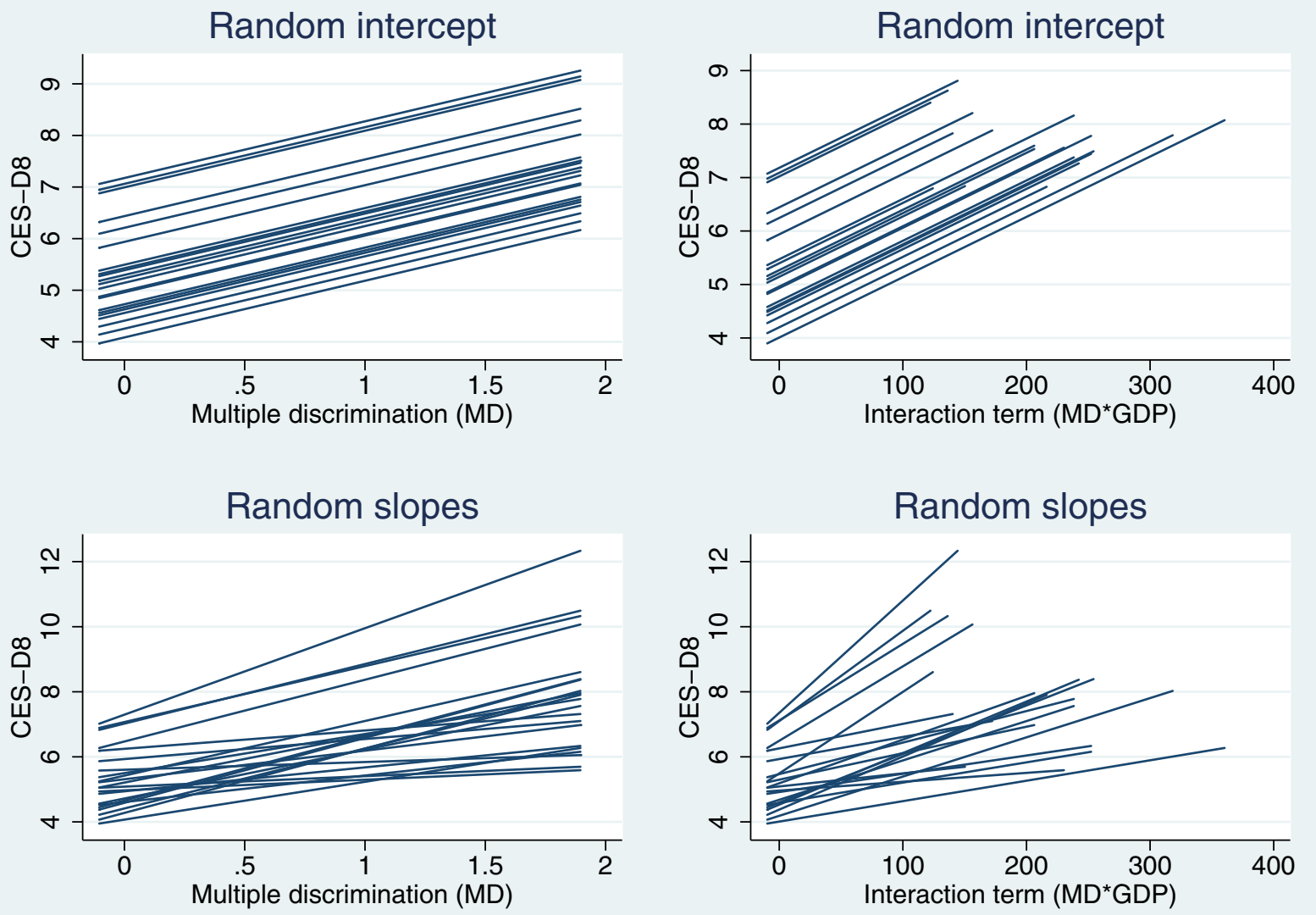

Fig. 1 Association between depressive symptoms and multiple discrimination in random intercept models and random slope models for main effect and crosslevel interactions

seems to be lower in wealthier European countries [31]. These findings have important implications to understand how the negative effect of combined forms of discrimination and subsequent stigmatisation might affect in countries characterised by socioeconomic problems (e.g. Eastern and Southern ones), and specifically in those that have been severely affected by the recent economic crisis [20].

Despite factors related to depression have been largely studied, the impact of multiple discrimination seems relatively unexplored and it has only been in recent years when it has drawn the attention of researchers [32]. The impact of multiple discrimination on depression should be breaking down in future research in order to assess the partial influence that may have on depressive disorders. Apart from socioeconomic, and racial and ethnic discrimination, our findings point out that other added forms of discrimination may have a negative impact on the people's mental health across Europe, especially in those countries less economically developed.
The notion of stigma has been defined as the phenomenon whereby an individual with an attribute is deeply discredited by his/her society and is rejected as a result of the attribute [...] a process by which the reaction of others spoils normal identity' [44]. This definition consider stigma as a consequence of a single socially rejected characteristic, but then what about those individuals that are socially labelled by multiple discrediting characteristics? Although there seem to be contextual variations in the association between multiple discrimination and the prevalence of depressive symptoms, this study shows that being discriminated by multiple reasons increases the risk of depressive symptoms in all European countries. Therefore, the harmful effects of multiple discrimination on psychological wellbeing and mental health should be considered to understand the subsequent impact on the quality of life of stigmatised groups [45]. All in all, we must consider that some individuals with discredited attributes can also have high self-esteem and good mental health, they can be happy and resilient to social discrimination experiences [46]. 


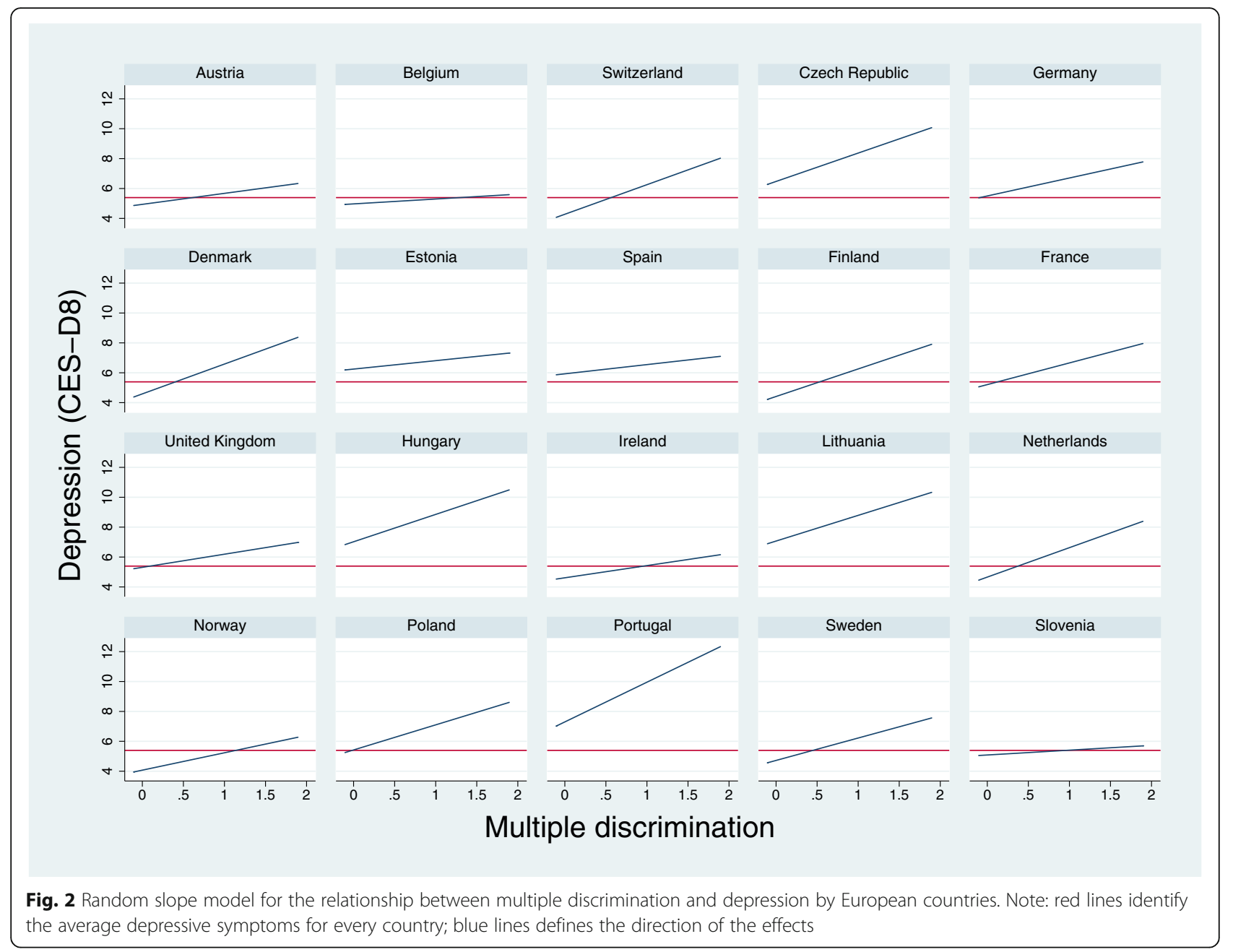

However, according our findings on the positive relationship between multiple discrimination and depressive symptoms, we must consider that resilience against discrimination feelings might be slowly undermined if the load of discrediting labels grows.

This study presents two main limitations that should be addressed in future research. On the one hand, the linear causation between multiple discrimination and depressive symptoms cannot be established since this work is based in cross-sectional data. For instance, reverse causation could also be possible (i.e. mentally ill people might present a higher predisposition to perceive discrimination). Studies has generally focused on perceived discrimination as a social determinant of health outcomes, but as recent works have demonstrated this theoretical assumption might be inverted as well [47]. In addition, although in this study we have considered a single-general measure of multiple discrimination, future works should address how do different types of discrimination are integrated in a single individual profile and how do different combinations of perceive discrimination might increase or reduce the risk of mental illness [41]. Evidence show that people suffering discrimination present different and specific problems. People with disabilities, LGBTI, immigrants, lower classes or the elderly, are different social groups characterized by specific norms, values, and social interest, thus future research should identify the concerns of concrete groups in context but also considering that multiple discredited characteristics can determine the health and wellbeing of single individuals.

\section{Conclusions}

The present study shows that the positive association between multiple discrimination and the prevalence of depressive symptoms in Europe might vary depending on the economic prosperity of every country. This finding provides new evidence on how this complex association operates at the micro and macro-level context, which is fundamental to understand how macro-economic fluctuations of countries may determine depressive disorders through the effect of single and combined forms of discrimination. Having this 
mechanism in mind, the future orientation of EU health and social policies should contribute to reduce the impact of social and economic inequalities in mental health in the most vulnerable groups, and especially to protect discriminated social groups against the lagging effects of the recent financial crisis.

\section{Acknowledgements}

We would like to acknowledge the support of the Spanish Ministry of Economy and Business and the Ramon \& Cajal programme, the IMPACT-A research group and the PSICOST Scientific Association, who yours contributed to the development of the present manuscript.

\section{Funding}

JAG is subsidised by the programme Ramon \& Cajal of the Ministry of Economy and Business (RYC-2016-19353). ARG was supported by the National Institute for Health Research (NIHR) Collaboration for Leadership in Applied Health Research and Care North Thames at Bart's Health NHS Trust (NIHR CLAHRC North Thames). The views expressed in this article are those of the author(s) and not necessarily those of the NHS, the NIHR, or the Department of Health and Social Care.

\section{Availability of data and materials}

This study is based on publicly available data from the European Social Survey (website: https://www.europeansocialsurvey.org/).

\section{Authors' contributions}

JAG designed the study in collaboration with ARG. JAG performed the exploitation and analysis of the database. JAG and ARG interpreted the results. Both authors read and approved the final manuscript.

\section{Ethics approval and consent to participate}

Not applicable.

\section{Consent for publication}

Not applicable.

\section{Competing interests}

The authors declare that they have no competing interests.

\section{Publisher's Note}

Springer Nature remains neutral with regard to jurisdictional claims in published maps and institutional affiliations.

\section{Author details}

${ }^{1}$ Department of Biomedicine, Biotechnology and Public Health, University of Cadiz, Avda. Ana de Viya, 52, 11009 Cádiz, Spain. ${ }^{2}$ NIHR CLAHRC North Thames, Department of Applied Health Research, University College London, 1-19 Torrington Place, London, London WC1E 7HB, UK.

Received: 7 November 2018 Accepted: 27 March 2019

Published online: 25 April 2019

\section{References}

1. Ferrari AJ, Charlson FJ, Norman RE, Patten SB, Freedman G, Murray CJ, Vos T, Whiteford HA. Burden of depressive disorders by country, sex, age, and year: findings from the global burden of disease study 2010. PLoS Med. 2013; 10(11):e1001547.

2. Vos T, Barber RM, Bell B, Bertozzi-Villa A, Biryukov S, Bolliger I, Charlson F, Davis A, Degenhardt L, Dicker D. Global, regional, and national incidence, prevalence, and years lived with disability for 301 acute and chronic diseases and injuries in 188 countries, 1990-2013: a systematic analysis for the global burden of disease study 2013. Lancet. 2015;386(9995):743-800.

3. World Health Organization. Depression and other common mental disorders: global health estimates. Geneva: World Health Organization; 2017.

4. Lorant V, Croux C, Weich S, Deliège D, Mackenbach J, Ansseau M. Depression and socio-economic risk factors: 7-year longitudinal population study. Br J Psychiatry. 2007;190(4):293-8.
5. Kessler RC, Bromet EJ. The epidemiology of depression across cultures. Annu Rev Public Health. 2013;34:119-38.

6. Wilkinson R, Marmot M. Social determinants of health: the solid facts. Copenhagen: World Health Organization; 2003.

7. Mackenbach JP. The persistence of health inequalities in modern welfare states: the explanation of a paradox. Soc Sci Med. 2012;75(4):761-9.

8. Albert MA, Ravenell J, Glynn RJ, Khera A, Halevy N, de Lemos JA. Cardiovascular risk indicators and perceived race/ethnic discrimination in the Dallas heart study. Am Heart J. 2008;156(6):1103-9.

9. Alvarez-Galvez J, Salvador-Carulla L. Perceived discrimination and self-rated health in Europe: evidence from the European Social Survey (2010). PLoS One. 2013;8(9):e74252.

10. Gee GC, Ro A, Shariff-Marco S, Chae D. Racial discrimination and health among asian americans: evidence, assessment, and directions for future research. Epidemiol Rev. 2009;31(1):130-51.

11. Gee GC, Spencer M, Chen J, Yip T, Takeuchi DT. The association between self-reported racial discrimination and 12-month DSM-IV mental disorders among Asian Americans nationwide. Soc Sci Med. 2007;64(10):1984-96.

12. Gomez J, Miranda R, Polanco L. Acculturative stress, perceived discrimination, and vulnerability to suicide attempts among emerging adults. J Youth Adolesc. 2011:40(11):1465-76.

13. Krieger N. Discrimination and health inequities. Int J Health Serv. 2014;44(4): 643-710.

14. Paradies Y. A systematic review of empirical research on self-reported racism and health. Int J Epidemiol. 2006;35(4):888-901.

15. Williams DR, Neighbors HW, Jackson JS. Racial/ethnic discrimination and health: findings from community studies. Am J Public Health. 2008;98(9 Suppl):S29-37.

16. Williams DR, Mohammed SA. Discrimination and racial disparities in health: evidence and needed research. J Behav Med. 2009:32(1):20-47.

17. Pascoe EA, Richman LS. Perceived discrimination and health: a meta-analytic review. Psychol Bull. 2009;135(4):531-54.

18. Todorova IL, Falcón LM, Lincoln AK, Price LL. Perceived discrimination, psychological distress and health. Sociol Health IIIn. 2010;32(6):843-61.

19. Bhui K, Stansfeld S, McKenzie K, Karlsen S, Nazroo J, Weich S. Racial/ethnic discrimination and common mental disorders among workers: findings from the EMPIRIC study of ethnic minority groups in the United Kingdom. Am J Public Health. 2005:95(3):496-501.

20. Borrell C, Muntaner C, Gil-González D, Artazcoz L, Rodríguez-Sanz M, Rohlfs I, Pérez K, García-Calvente M, Villegas R, Álvarez-Dardet C. Perceived discrimination and health by gender, social class, and country of birth in a southern European country. Prev Med. 2010;50(1-2):86-92.

21. De Castro AB, Gee GC, Takeuchi DT. Workplace discrimination and health among Filipinos in the United States. Am J Public Health. 2008;98(3):520-6.

22. Hunte HER, Williams DR. The association between perceived discrimination and obesity in a population-based multiracial and multiethnic adult sample. Am J Public Health. 2009;99(7):1285-92

23. Veling W, Hoek HW, Mackenbach JP. Perceived discrimination and the risk of schizophrenia in ethnic minorities. Soc Psychiatry Psychiatr Epidemiol. 2008;43(12):953-9.

24. Nazroo JY. The structuring of ethnic inequalities in health: economic position, racial discrimination, and racism. Am J Public Health. 2003;93(2): 277-84.

25. Alvarez-Galvez J. Measuring the effect of ethnic and non-ethnic discrimination on Europeans' self-rated health. Int J Public Health. 2016; 61(3):367-74.

26. Bradford J, Reisner SL, Honnold JA, Xavier J. Experiences of transgenderrelated discrimination and implications for health: results from the Virginia transgender health initiative study. Am J Public Health. 2013;103(10):1820-9.

27. Ferrie JE, Head J, Shipley MJ, Vahtera J, Marmot MG, Kivimäki M. Injustice at work and incidence of psychiatric morbidity: the Whitehall II study. Occup Environ Med. 2006;63(7):443-50.

28. Kim SS, Williams DR. Perceived discrimination and self-rated health in South Korea: a nationally representative survey. PLoS One. 2012;7(1): e30501.

29. Oli N, Onta SR. Self-perception of stigma and discrimination among men having sex with men. J Nepal Health Res Counc. 2012;10(22):197-200.

30. Cea D'Ancona MÁ. Measuring multiple discrimination through a surveybased methodology. Soc Sci Res. 2017;67:239-51.

31. European Commission. Directorate-General for Employment, Equal Opportunities. Unit G.. Tackling multiple discrimination: practices, policies 
and laws. Luxembourg: Office for Official Publications of the European Communities; 2007.

32. Gayman MD, Barragan J. Multiple perceived reasons for major discrimination and depression. Soc Ment Health. 2013;3(3):203-20.

33. Missinne S, Bracke P. Depressive symptoms among immigrants and ethnic minorities: a population based study in 23 European countries. Soc Psychiatry Psychiatr Epidemiol. 2012;47(1):97-109.

34. Levecque K, Van Rossem R. Depression in Europe: does migrant integration have mental health payoffs? A cross-national comparison of 20 European countries. Ethn Health. 2015;20(1):49-65.

35. Mayda AM. Who is against immigration? A cross-country investigation of individual attitudes toward immigrants. Rev Econ Stat. 2006;88(3):510-30.

36. Round E. 7: European Social Survey Round 7 Data. In: Norwegian Social Science Data Services, Norway; 2014) Data file.

37. ESS round 7: European social survey: ESS-7 2014 documentation report edition 31 European social survey data archive 2016.

38. Radloff LS. The CES-D scale: a self-report depression scale for research in the general population. Appl Psychol Meas. 1977;1(3):385-401.

39. Eikemo TA, Bambra C, Huijts T, Fitzgerald R. The first pan-european sociological health inequalities survey of the general population: the european social survey rotating module on the social determinants of health. Eur Sociol Rev. 2017;33(1):137-53.

40. Raudenbush SW, Bryk AS. Hierarchical linear models: applications and data analysis methods. Thousand Oaks: Sage Publications Inc;; 2002.

41. Cormack D, Stanley J, Harris R. Multiple forms of discrimination and relationships with health and wellbeing: findings from national crosssectional surveys in Aotearoa/New Zealand. Int J Equity Health. 2018; 17(1):26.

42. Grollman EA. Multiple disadvantaged statuses and health: the role of multiple forms of discrimination. J Health Soc Behav. 2014:55(1):3-19.

43. Stuber J, Galea S, Ahern J, Blaney S, Fuller C. The association between multiple domains of discrimination and self-assessed health: a multilevel analysis of Latinos and blacks in four low-income new York City neighborhoods. Health Serv Res. 2003;38(6p2):1735-60.

44. Goffman E. Stigma: notes on the management of spoiled identity. New York: Simon and Schuster Inc.; 1963.

45. Slater LZ, Moneyham L, Vance DE, Raper JL, Mugavero MJ, Childs G. The multiple stigma experience and quality of life in older gay men with HIV.J Assoc Nurses AIDS Care. 2015;26(1):24-35.

46. Heatherton TF, Kleck RE, Hebl MR, Hull JG. The social psychology of stigma. New York: Guilford Press.; 2000

47. Alvarez-Galvez J. Discovering complex interrelationships between socioeconomic status and health in Europe: a case study applying Bayesian networks. Soc Sci Res. 2016;56:133-43.

Ready to submit your research? Choose BMC and benefit from:

- fast, convenient online submission

- thorough peer review by experienced researchers in your field

- rapid publication on acceptance

- support for research data, including large and complex data types

- gold Open Access which fosters wider collaboration and increased citations

- maximum visibility for your research: over $100 \mathrm{M}$ website views per year

At $\mathrm{BMC}$, research is always in progress.

Learn more biomedcentral.com/submissions 